Gut, 1989, 30, 1716-1720

\title{
Studies on the pathogenesis of the early dumping syndrome induced by intraduodenal instillation of hypertonic glucose
}

\author{
J A SNOOK, A D WELLS, D R PRYTHERCH, D H EVANS, S R BLOOM, \\ AND D G COLIN-JONES
}

From the Queen Alexandra Hospital, Portsmouth, Hampshire, Hammersmith Hospital, London, and Leicester Royal Infirmary, Leicester

SUMmary A reaction indistinguishable from the early dumping syndrome was induced in four of nine normal volunteers by intraduodenal instillation of a hypertonic glucose meal. Tachycardia and marked peripheral vasodilatation were demonstrated in 'dumpers' by Doppler ultrasound measurements of the arterial blood flow signal. The dumping reaction was not detectably altered by the addition of guar to the meal. Plasma VIP concentration rose and plasma volume fell to a similar degree in 'dumpers' and 'non-dumpers', suggesting that neither event is an integral component of the dumping mechanism. In contrast, the rates of rise of blood glucose and enteroglucagon concentration were markedly greater in 'dumpers'. The results are inconsistent with the conventional explanation that the early dumping syndrome is caused by a large osmotic fluid shift, but are compatible with a mechanism involving an initial period of intestinal hypermotility.

The dumping syndrome remains a cause of morbidity after gastric surgery.' A plethora of associated gastrointestinal, cardiovascular and hormonal abnormalities have been described. ${ }^{-7}$ Because of their close inter-relationship, however, it has not been possible to determine which of these abnormal responses are integral components of the dumping mechanism and which are purely epiphenomena.

There is general agreement that accelerated early gastric emptying of liquids is a characteristic feature and a critical initial step in the pathogenesis of the dumping syndrome. ${ }^{+\infty}$ It has previously been shown that rapid instillation of liquid meals into the small bowel can induce dumping symptoms in normal individuals." "I Dumpers and non-dumpers, however, show some overlap in their rate of gastric emptying, ${ }^{+}$ and not all normal subjects can be induced to dump in instillation experiments. "' The rate of gastric emptying is therefore not the only determinant of whether dumping will occur. We have attempted to define the nature of subsequent events in the pathogenesis of

Address for correspondence: Dr J A Snook, Royal Hampshire County Hospital, Winchester, Hants.

Accepted for publication 31 March 1989 dumping by intraduodenal instillation of hypertonic glucose in normal subjects.

\section{Methods}

SUBJECTS

Nine healthy male volunteers (median age 25 years) were studied after an overnight fast. A 12 gauge single lumen tube was passed into the mid-duodenum under fluoroscopic control. After a stabilisation period of at least 15 minutes, a liquid test meal of 150 $\mathrm{ml} 50 \%$ glucose (meal 1) was instilled over 10 minutes. Subjects remained seated for the duration of the study. The subjects, all medically trained, were asked beforehand to volunteer symptoms as they developed, and at the end of the test to grade the severity of any reaction in discussion with one of the investigators.

Three of the four subjects who developed convincing features of the early dumping syndrome were given a second instillation (meal 2) at least two weeks after meal 1 . This consisted of $150 \mathrm{ml} 50 \%$ glucose intimately mixed with 5 g guar gum (Glucotard; MCP Pharmaceuticals). 
Serial blood samples were taken with minimal stasis for estimation of haematocrit and assay of glucose and gastrointestinal hormones (insulin, vasoactive intestinal polypeptide (VIP), and enteroglucagon). Plasma volume changes were calculated from the haematocrit by a previously validated method." 11 The samples for gut hormone assay were collected in lithium heparin tubes containing aprotinin $(4000 \mathrm{KIU})$, and the extracted plasma was frozen at $-20^{\circ} \mathrm{C}$ within 15 minutes of collection. Hormone assays were performed by the Francis Fraser Laboratory, Hammersmith Hospital using established techniques.'2

Serial Doppler waveforms were recorded from the most convenient of the right dorsalis pedis or posterior tibial artery. The pulsatility index was calculated from tape recordings of the Doppler ultrasound blood flow signals using a spectrum analyser/computer system. ${ }^{13}$ The pulsatility index is the ratio of the maximum minus the minimum value of the signal maximum frequency envelope over one cardiac cycle to the mean value of the maximum frequency envelope over the same period. ${ }^{14}$ The median pulsatility index value for at least 30 consecutive beats was taken as a measure of the degree of peripheral vasoconstriction. ${ }^{15} 10$

The study was approved by the Ethical Committee of the District Health Authority. The results were analysed using the Mann-Whitney $\mathrm{U}$ test.

\section{Results}

\section{SYMPTOMS}

Four of the nine subjects (henceforth dumpers) developed moderate to severe dumping symptoms beginning five to 15 minutes after the end of the instillation of meal 1. All four reported multiple recognised symptoms of the dumping syndrome' of both visceral and systemic origin. Symptoms volunteered included abdominal discomfort and distension, nausea, malaise, somnolence, sweating, headache, palpitations and a feeling of warmth. The other five subjects experienced minimal or no symptoms (henceforth non-dumpers). Meal 2 induced symptoms similar in nature and severity to the first meal in all three dumpers rechallenged.

\section{PLASMA VOLUME}

The calculated individual peak falls in plasma volume ranged from $4.0 \%$ to $14.9 \%$. The mean peak fall in plasma volume with meal 1 was similar in nondumpers $(7 \cdot 3 \%)$ and dumpers $(7 \cdot 7 \%)$.

\section{GLUCOSE AND INSUI.IN}

The mean blood glucose profiles are shown in Figure 1. The initial rate of rise of glucose concentration

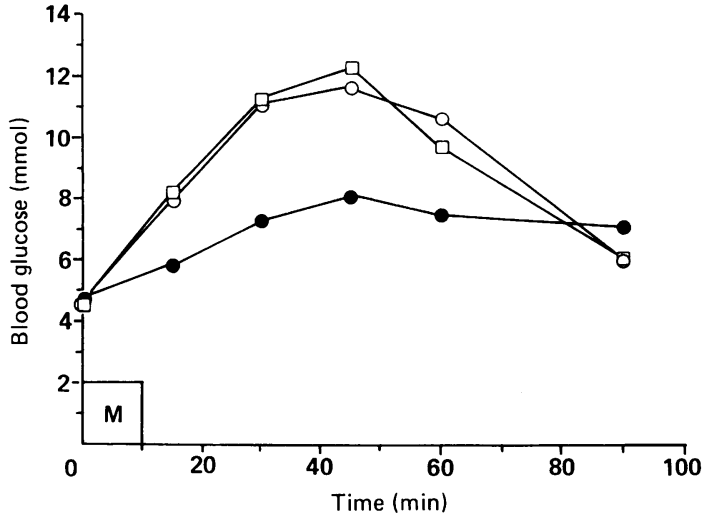

Fig. 1 Mean blood glucose profile in non-dumpers (O $n=5)$, dumpers with meal $1(\bigcirc: n=4)$, and dumpers with meal $2(\square: n=3)$. The timing of the meal is indicated $(M)$.

with meal 1 was markedly greater in dumpers ( range: $5.4-8.3 \mathrm{mmol} / \mathrm{l} / 30$ minutes) than non-dumpers $(1.5$ $4 \cdot 2 \mathrm{mmol} / \mathrm{l} / 30$ minutes: $\mathrm{p}<0 \cdot 05)$. The peak glucose concentration was correspondingly higher in dumpers but had returned almost to normal by 90 minutes. Peak insulin concentrations were higher and delayed in dumpers (Fig. 2), presumably the consequence of higher glucose concentrations and the cause of the accelerated fall in plasma glucose concentration seen after 60 minutes.

ENTEROGLUCAGON

The mean enteroglucagon profiles are shown in Figure 3. The initial rate of rise of enteroglucagon concentration with meal 1 was significantly greater in dumpers (range: 195-435 pmol/1/30 minutes) than non-dumpers (73-182 pmol/l/30 minutes: $\mathrm{p}<0 \cdot 05)$. There was a strong positive correlation between the

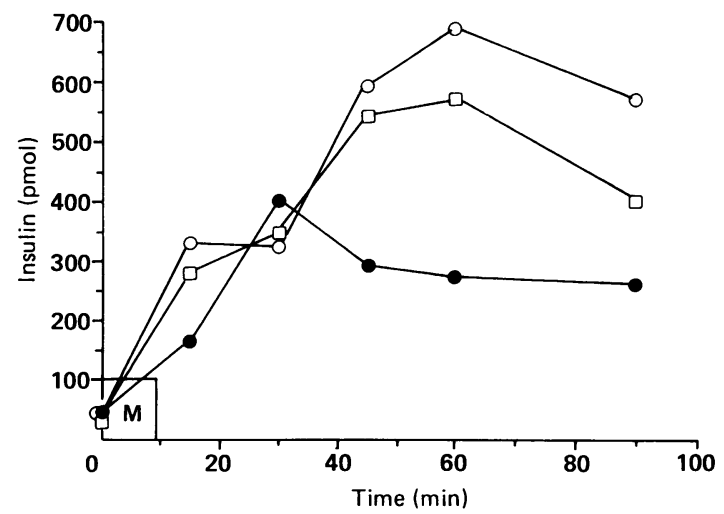

Fig. 2 Mean plasma insulin profile in non-dumpers (O: $(n=5)$, dumpers with meal I $(\mathrm{O}: n=4)$, and dumpers with meal 2 ( $\square: n=3$ ). The timing of the meal is indicated $(M)$. 
1718

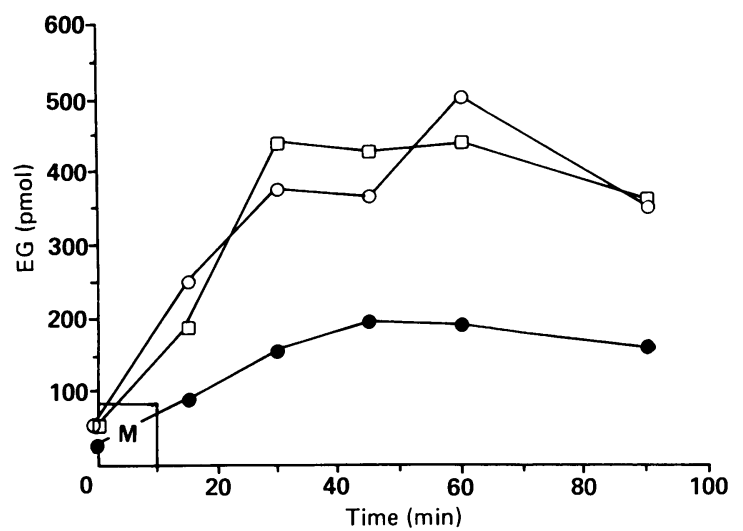

Fig. 3 Mean plasma enteroglucagon (EG) profile in nondumpers (O: $n=5)$, dumpers with meal $1(\bigcirc: n=4)$, and dumpers with meal $2(\square: n=3)$. The timing of the meal is indicated $(M)$.

rates of rise of glucose and enteroglucagon (for meal $1, r=0 \cdot 86, p<0 \cdot 01$; Fig. 4$)$.

VIP

A similar modest rise in VIP concentration occurred after meal 1 in dumpers (range: $0-6 \mathrm{pmol} / 1 / 30$ minutes) and non-dumpers ( $(0-6 \mathrm{pmol} / \mathrm{l} / 30$ minutes: ns).

\section{CARDIOVASCULAR PARAMETERS}

The overall mean initial values of heart rate and pulsatility index (1 SD) were $68(14) \mathrm{bpm}$ and 11.4 $(4 \cdot 6)$ respectively. Both parameters showed a degree

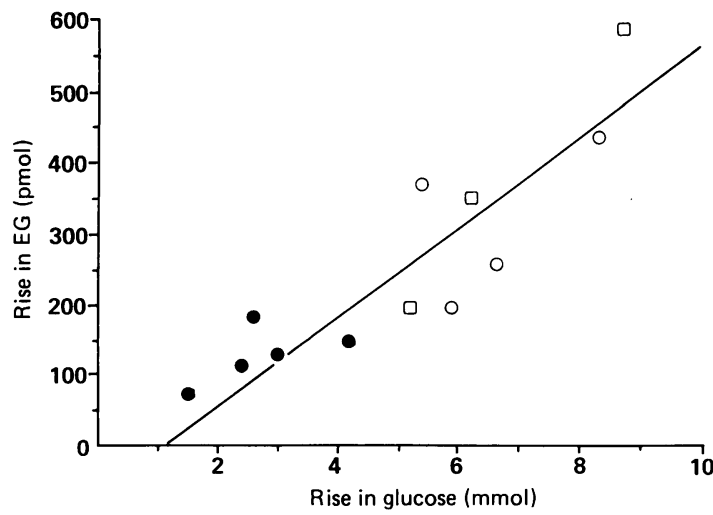

Fig. 4 Relationship between the rise in enteroglucagon (EG) and glucose concentrations over 30 minutes from the start of the meal in non-dumpers $(\mathbf{O}: n=5)$, dumpers with meal $1(\bigcirc: n=4)$, and dumpers with meal $2(\square: n=3)$. The regression line for the results with meal $I$ is shown $(r=0 \cdot 86$, $p<0 \cdot 01)$.
Snook, Wells, Prytherch, Evans, Bloom, and Colin-Jones

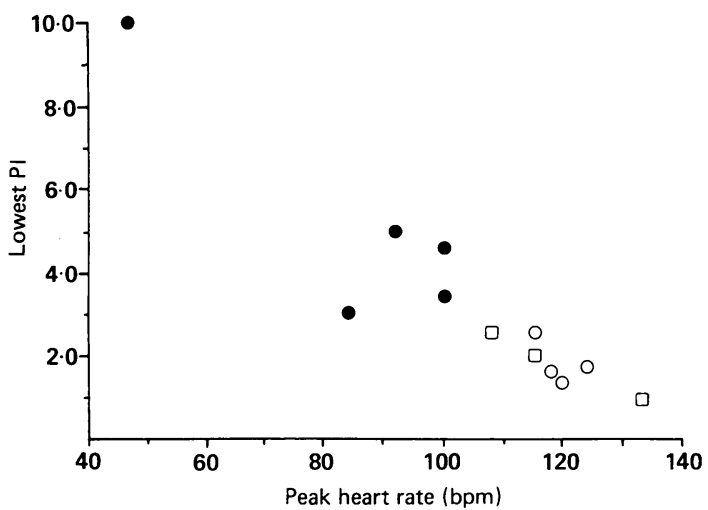

Fig. 5 Relationship between peak heart rate and lowest pulsatility index $(P I)$ within one hour of the start of the meal in non-dumpers $(O: n=5)$, dumpers with meal $I(O: n=4)$, and dumpers with meal $2(\square: n=3)$. Pulsatility index falls with increasing vasodilatation.

of fluctuation during the course of the study in all subjects. Dumpers were, however, clearly characterised by an exaggerated fall in pulsatility index, indicating peripheral vasodilatation, and a marked rise in heart rate (Fig. 5). In all seven studies in which dumping was induced, the peak heart rate occurred at the time of or just before the lowest recorded pulsatility index, generally when symptoms were particularly prominent.

\section{Discussion}

By mimicking rapid gastric emptying in a standardised manner, we have attempted to assess the contribution of subsequent events to the pathogenesis of the early dumping syndrome. The relatively small number of subjects risks both type I and type II errors in the interpretation of the results, but several inferences may be drawn.

The study has confirmed the observation that rapid instillation of a liquid test meal into the small bowel can induce a reaction in a proportion of normal individuals which is indistinguishable from the early dumping syndrome "I"; a small number of patients with the early dumping syndrome given oral hypertonic glucose have shown comparable changes in the parameters assessed (results not shown). The failure of guar to modify the experimental dumping response suggests that any therapeutic effect it may have is the result of retardation of gastric emptying alone. ${ }^{*}$ :

The standard explanation for early dumping implicates a major osmotic shift of water from the extracellular compartment to the lumen of the small bowel. Consequent distension is postulated to 
account for the gastrointestinal symptoms, and hypovolaemia for the systemic features. ${ }^{1 \mathrm{~S}}$ There are already reasons for doubting this hypothesis. First, the severity of dumping is not reliably related to the volume of hypertonic solution ingested." Second, intravenous infusion sufficient to prevent the postprandial fall in plasma volume may not abolish (systemic) dumping symptoms. ${ }^{3}$ Third, intravenous somatostatin abolishes dumping ${ }^{11}$ : yet by accelerating gastric emptying" and inhibiting small bowel absorptive function:-1 it might reasonably be expected to exaggerate any osmotic effect.

Our results provide further evidence against the osmotic load hypothesis. First, the mean plasma volume fall in non-dumpers was similar to that in dumpers. This suggests that an exaggerated fall in plasma volume is purely a consequence of rapid gastric emptying, with which it has been shown to be closely associated ${ }^{+5}$ and is not a cause of dumping symptoms. Second, the Doppler studies confirm the previous suggestion ${ }^{22} 23$ that peripheral vasodilatation is an integral feature of the dumping syndrome. If volume depletion were responsible for the cardiovascular changes then reflex vasoconstriction might be expected.

What clues do our results provide about the pathogenesis of the dumping syndrome? There is no support for the hypothesis that VIP is an important factor, as peak concentrations were similar in dumpers and non-dumpers, and were far lower than are needed to show vasoactive effects. ${ }^{24}$ The striking finding was the difference in rates of rise of glucose and enteroglucagon concentrations between dumpers and non-dumpers. Similar differences have previously been shown in patients after an oral glucose load, ${ }^{6 \times 25}$ but what is clear from this study.is that these abnormal responses persist after controlling for the rate of gastric emptying.

Stimulation of osmoreceptors in the duodenum has been shown to induce intestinal hypermotility, ${ }^{26}$ and an early period of hypermotility has been shown by various means in patients with the dumping syndrome. ${ }^{.7-24}$ This provides a plausible unifying explanation for the exaggerated rates of rise of glucose and enteroglucagon seen in dumpers. Accelerated transit of the liquid bolus through the small bowel might be expected to enhance the stimulus to ileocolonic enteroglucagon release. ${ }^{\times 5} \mathrm{At}$ the same time, exposure of a greater area of absorptive surface would be predicted to enhance the rate of glucose absorption, in particular because the intestinal active transport mechanism for glucose saturates at glucose concentrations an order of magnitude lower than that used in this study. ${ }^{31.31}$ Interestingly, only a proportion of normal subjects respond to intraduodenal instillation of hypertonic solution with a regular pattern of motor activity, and this could explain the fundamental difference between dumpers and non-dumpers.

In conclusion, our observations on the early dumping syndrome are inconsistent with the osmotic load hypothesis. Intestinal hypermotility may account for visceral symptoms of the syndrome. The mediator of the systemic component remains to be identified; possibilities include an unidentified ileal hormone and a ncural reflex arc.

We gratefully acknowledge the financial support of MCP pharmaecuticals.

\section{References}

1 Ralphs DNL. The dumping syndrome. Br J Clin Pract 1981; 35: 291-3.

2 Le Quesne LP. Hobsley M. Hand BH. The dumping syndrome. Br Med J 1960); i: 141-7.

3 Christoffersson E, Hallberg L, Lindell SE. Solvell L. Westling $\mathrm{H}$. Some circulatory reactions during provoked dumping. Acta Chir Scand 1965; 130: 224-36.

4 Ralphs DNL. Thomson JPS. Haynes S, Lawson-Smith C. Hobsley M, Le Quesne L.P. The relationship between the rate of gastric emptying and the dumping syndrome. BrJ Surg 1978; 65: 6.37-41.

5 Lawactz O. Aritas Y, Blackburn AM, Ralphs DNL. Gastric emptying after peptic ulcer surgery. Scand $J$ Gastroenterol 1982; 17: 1065-72.

6 Lawactz O, Blackburn AM, Bloom SR, Aritas $\mathrm{Y}$, Ralphs DNL. Gut hormone profile and gastric emptying in the dumping syndrome. Scand J Gastroenterol 1983; 18: $73-80$.

7 Kaushik SP, Ralphs DNL, Hobsley M. Influences on the occurrence of dumping syndrome. Am J (jastroenterol $1983 ; 78$ : $155-8$.

8 Jenkins DJA, Bloom SR. Albuquerque RH, et al. Pectin and complications after gastric surgery: normalisation of postprandial glucose and endocrine responses. Gut 1980; 21: 574-9.

9 Machella TE. The mechanism of post-gastrectomy dumping syndrome. Ann Surg 1949; 130: 14.5-.59.

10 Fenger HJ. The dumping disposition in normal persons. Acta Chir Scand 1965; 129: 201-10.

11 Sigstad $\mathrm{H}$. A clinical diagnostic index in the diagnosis of the dumping syndrome. Acta Med Scand 1970; 188: 47986.

12 Bloom SR, Long RG, eds. Radioimmunoassay of gut regulatory peptides. London: WB Saunders, 1982.

13 Prytherch DR, Evans DH. Versatile microcomputerbased system for the capture, storage and processing of spectrum-analysed Doppler ultrasound blood flow signals. Med Biol Eng Comput 1985; 23: 445-52.

14 Gibbons DT, Evans DH, Barric WW, Cosgriff PS. Real-time calculation of ultrasonic pulsatility index. Med Biol Eng Comput 1981; 19: 28-34.

15 Evans DH, Barric WW. Asher MJ, Bentley S, Bell PRF. The relationship between ultrasonic pulsatility index and proximal arterial stenosis in a canine model. Circ Res 1980; 46: 47()-5. 
16 Clifford PC, Martin MFR, Sheddon EJ, Kirby JD, Baird RN, Dieppe PA. Treatment of vasospastic disease with prostaglandin E1. Br Med J 1980; 281: 1031-4.

17 Harju E, Hcikkila J, Larmi TKI. Effect of guar gum on gastric emptying after gastric resection. J Parent Ent Nutr 1983: 8: 18-20.

18 Hobsley M. Dumping and diarrhoca. BrJ Surg 1981; 68: $681-4$.

19 Long RG, Adrian TE, Bloom SR. Somatostatin and the dumping syndrome. Br Med J 1985; 290: 886-8.

20 Long RG, Christofides ND, Fitzpatrick ML, O'Shaughnessy DJ, Bloom SR. Effect of intravenous somatostatin and motilin on the blood glucose and hormonal response to oral glucose. Eur J Clin Invest $1982 ; 12: 331-6$.

21 Krejs GJ, Browne R, Raskin P. Effect of intravenous somatostatin on jejunal absorption of glucose, amino acids, water and electrolytes. Gastroenterology 1980; 78: 26-31.

22 Cox HT, Allan WR. The dumping syndrome. Lancet 1961: ii: $672-4$.

23 Hinshaw DB, Joergenson EJ, Davis HA, Stafford CE. Peripheral blood flow and blood volume studies in the dumping syndrome. Arch Surg 1957; 74: 686-93.
24 Domschke S, Domschke W, Bloom SR, et al. Vasoactive intestinal polypeptide in man: pharmacokinetics, metabolic and circulatory effects. Gut 1978; 19: 1049-53.

25 Bloom SR, Royston CMS. Thomson JPS. Enteroglucagon release in the dumping syndrome. Lancet 1972; ii: 789-91.

26 Thompson DG. Wingate DL. Effects of osmoreceptor stimulation on human duodenal motor activity. Gut 1988; 29: 173-80.

27 Glazebrook AJ. Welbourn RB. Some observations on the function of the small intestine after gastrectomy. BrJ Surg 1952; 40: 111-7.

28 Pernow B, Wallensten S. The dumping syndrome. Acta Chir Scand 1964; 128: 530-40.

29 Christoffersson E, Kewenter J, Koch NG. Intestinal motility during provoked dumping reaction. Acta Chir Scand 1962: 123: 405-14.

30 Saltzman DA, Rector FC, Fordtran JS. The role of intraluminal sodium in glucose absorption in vivo. $J$ Clin Invest 1972; 51: 876-85.

31 Bicberdorf FA, Morawski S. Fordtran JS. Effect of sodium, mannitol and magnesium on glucose, galactose, 3-o-methylglucose and fructose absorption in the human ilcum. Gastroenterology 1975; 68: 58-66. 